\title{
Antioxidant effects of carotenoids in a model pigment-protein complex*
}

\author{
Joanna Fiedor ${ }^{\circledR}$, Aleksandra Sulikowska", Aleksandra Orzechowska', Leszek Fiedor ${ }^{2}$ and \\ Květoslava Burda'
}

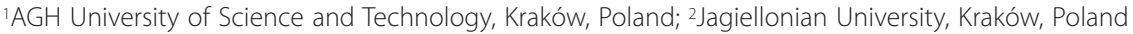

\begin{abstract}
The effect of carotenoids on stability of model photosynthetic pigment-protein complexes subjected to chemical oxidation with hydrogen peroxide or potassium ferricyanide was investigated. The oxidation of carotenoid-less and carotenoid-containing complexes was conducted in the presence or absence of ascorbic acid. The progress of the reactions was monitored by use of absorption and fluorescence spectroscopy. Our results show that carotenoids may significantly enhance the stability of photosynthetic complexes against oxidation and their protective (antioxidant) effect depends on the type of the oxidant.
\end{abstract}

Key words: carotenoid, chemical oxidation, antioxidant, stability

Received: 24 October, 2011; accepted: 01 March, 2012;

available on-line: 17 March, 2012

\section{INTRODUCTION}

The photosynthetic apparatus in purple photosynthetic bacteria comprises reaction centers and light harvesting pigment protein complexes LH1 and LH2. The latter, i.e. the peripheral antenna complex, is not produced by all bacterial species. The crystal structures of LH2 complexes from several species of phototrophic bacteria were solved with a high resolution $(\mathrm{McD}$ ermott et al., 1995; Koepke et al., 1996) while the structure of LH1 is known in less detail. As shown by Ghosh et al. (1988) each complex is composed of identical blocks of low molecular weight and very hydrophobic $\alpha$ - an $\beta$-apoproteins to which bacteriochlorophylls (BChls) and carotenoids (Crts) are non-covalently attached (Cogdell et al., 1996). In the absence of Crts, the pigment-polypeptide units spontaneously oligomerize to form the complex whose main absorption maximum is located near $870 \mathrm{~nm}$. In the presence of Crts this band shifts to 880 $\mathrm{nm}$ (in the case of Rhodospirillum rubrum). In micellar media, the Crt-less LH1 (B870) reversibly dissociates into monomeric subunits (Loach et al., 1995; Fiedor et al., 2009). The ability of B870 to undergo reversible dissociation renders the complex a unique model system that allows for investigation of interactions occurring between its components. The oligomerization and reconstitution of LH1 from its native or chemically modified components has been studied extensively (Davidson et al., 1981; Miller et al., 1987; Strugis et al., 1994; Frank, 1999; Pandit et al., 2001). Also a full reconstitution, including all components of the LH1 antenna was achieved (Davis et al., 1995; Fiedor et al., 2001b; Fiedor et al., 2004; Fiedor et al., 2009).
It has been shown that BChl components of LH1 complexes undergo oxidation upon treatment with potassium ferricyanide. Such treatment leads to changes in the absorption, circular dichroism (CD), fluorescence emission, and electron paramagnetic resonance spectral signals of the complex (Gomez et al., 1982; Picorel et al., 1984; Law et al., 1998). We have previously studied the effects of Crts on stability of BChla and its derivatives in a model system (Fiedor et al., 2001a; Fiedor et al., 2002), however, so far, the effect of Crts on stability of LH1 complexes exposed to chemical oxidation has not been demonstrated. Crts are structurally and functionally a very diverse group of isoprenoid pigments (Britton, 1995). They occur in all photosynthetic organisms in which they carry out various functions, with light harvesting and (photo)protection considered as the most important. Crts act both as physical quenchers of (B)Chl excited states and efficient scavengers of reactive oxygen species (ROS). They also act as chemical quenchers of ROS undergoing irreversible modifications that may be responsible for a change from the antioxidant to prooxidant activity (Fiedor et al., 2001a; Fiedor et al., 2005).

In the present paper, we demonstrate our results on the role of Crts in stabilization of pigment-protein complexes against chemical oxidation. The model Crtcontaining and Crt-less LH1 complexes were subjected to chemical oxidation with hydrogen peroxide or potassium ferricyanide. The antioxidant and stabilizing activity of Crt was monitored by following the changes in the electronic absorption and fluorescence emission spectra of the oxidized complexes.

\section{MATERIALS AND METHODS}

Isolation of spheroidene. Spheroidene (Sph) was isolated from the cells of Rhodobacter sphaeroides 2.4.1 as described in Fujii et al. (1998) with minor modifications. The purity of the isolated Sph was checked spectrophotometrically and by HPLC (Fiedor, 2007).

Preparation of B870. Crt-depleted LH1 was prepared as described by Fiedor et al. (2004; 2009) and used immediately after preparation.

e-mail: Joanna.Fiedor@fis.agh.edu.pl

* Presented at the 16th International Symposium on Carotenoids, 17-22 July, 2011, Kraków, Poland

\#Work performed in partial fulfillment for the M.Sc. degree

Abbreviations: AA, ascorbic acid; BChl, bacteriochlorophyll; B870, carotenoid-devoid light harvesting complex 1 with the main absorption band near $870 \mathrm{~nm}$; CD, circular dichroism; Crt, carotenoid; $\mathrm{LH}$, light harvesting complex; ROS, reactive oxygen species; Sph, spheroidene; Sph-LH1, light harvesting complex 1 reconstituted with spheroidene. 
Reconstitution assay. The incorporation of Sph into LH complexes was carried out as described previously (Fiedor et al., 2004). Briefly, for the reconstitution, a portion of bacterial Crt-less LH1 in $0.033 \%$ LDAO was titrated with a solution of $\mathrm{Sph}$ in acetone $\left(\mathrm{OD}_{457 \mathrm{~nm}}\right.$ 1.2). The progress of the reconstitution was monitored by absorption spectroscopy. The reconstitution was considered complete when a red shift of the LH1 $\mathrm{Q}_{\mathrm{Y}}$ band from $873 \mathrm{~nm}$ to $880 \mathrm{~nm}$ was observed. The freshly prepared Sph-binding LH1 (Sph-LH1) was kept overnight at $4^{\circ} \mathrm{C}$ and used without further purification.

Chemical stability of B870 and Sph-LH1. The resistance of Crt-less and Sph-containing LH1 complexes toward chemical oxidation was tested in reactions with hydrogen peroxide $(70 \mathrm{mM}, 150 \mathrm{mM}$ and $290 \mathrm{mM}$ ) or potassium ferricyanide (25 $\mathrm{mM}, 50 \mathrm{mM}$, and $100 \mathrm{mM}$ ) in the absence or presence of $1 \mathrm{mM}$ ascorbic acid (AA). The progress of the oxidation was monitored by following the changes in the absorption (Cary50 Bio, Varian) and fluorescence emission spectra (FluoroMax-P, Horiba Jobin Yvon). The spectra were recorded just before addition of an oxidant, and then after being kept in the dark for $5,15,30,45,60,75$ and $90 \mathrm{~min}$ at room temperature. Simultaneously, control (no oxidant) experiments were performed.

\section{RESULTS AND DISCUSSION}

The model Crt-less B870 and Crt-containing LH1 complexes were prepared following the published procedures (Fiedor et al., 2004; Fiedor, 2006; Fiedor et al., 2009). The absorption spectrum of B870 exhibits a characteristic maximum at $875 \mathrm{~nm}$ assigned to the $\mathrm{BChl} \mathrm{Q}_{\mathrm{Y}}$ transition (Fig. 1A). The excitation at the $\mathrm{BChl} \mathrm{Q}_{\mathrm{X}}$ band $(590 \mathrm{~nm})$ results in the emission of fluorescence with a maximum at $890 \mathrm{~nm}$. A strong conservative signal, with a minimum at $849 \mathrm{~nm}$, a maximum at $884 \mathrm{~nm}$ and a crossover point at $\sim 872 \mathrm{~nm}$ are characteristic features of the $\mathrm{CD}$ spectrum of $\mathrm{B} 870$. In the $\mathrm{Q}_{\mathrm{X}}$ range, a prominent positive signal is also present (Fig. 1A, inset). The spectral properties of $\mathrm{B} 870$ are consistent with those described in the literature (Picorel et al., 1983; Chang et al., 1990; Fiedor et al., 2009).

A recently developed method of the LH1 reconstitution was applied to prepare model Crt-containing complex. Crts are known to have a high affinity to Crt-less LH1 subunits, resulting in changes of thermodynamic parameters of the LH1 formation (Fiedor et al., 2009). Sph, a bacterial acyclic Crt, with one metoxy group and 10 conjugated double bonds, was incorporated to the BChl-protein matrix. The absorption spectrum of reconstituted Sph-LH1 (Fig. 1B) resembles the spectrum of native LH1 (Fiedor et al., 2004). It exhibits a strong transitions in the NIR range (around $880 \mathrm{~nm}$ ) and Crt bands with characteristic for Sph maxima at 442, 470 and 502 $\mathrm{nm}$. The excitation of Sph-LH1 at $470 \mathrm{~nm}$ results in an emission spectrum with a maximum at $898 \mathrm{~nm}$. The correctness of the reconstitution process was evidenced by the efficient Crt-to-BChl singlet energy transfer. As estimated from the excitation spectrum of the Sph-LH1, it occurs with the efficiency of about $85 \%$. This is in agreement with the value previously reported for LH1 complexes containing Sph (Noguchi et al., 1990; Akahane et al., 2004).

The Sph-LH1 complex was also characterized by the use of the CD technique. The CD spectrum shows a weak conservative signal in the NIR region with the crossover point at $\sim 881 \mathrm{~nm}$ (Fig. 1B, inset). Other sig-
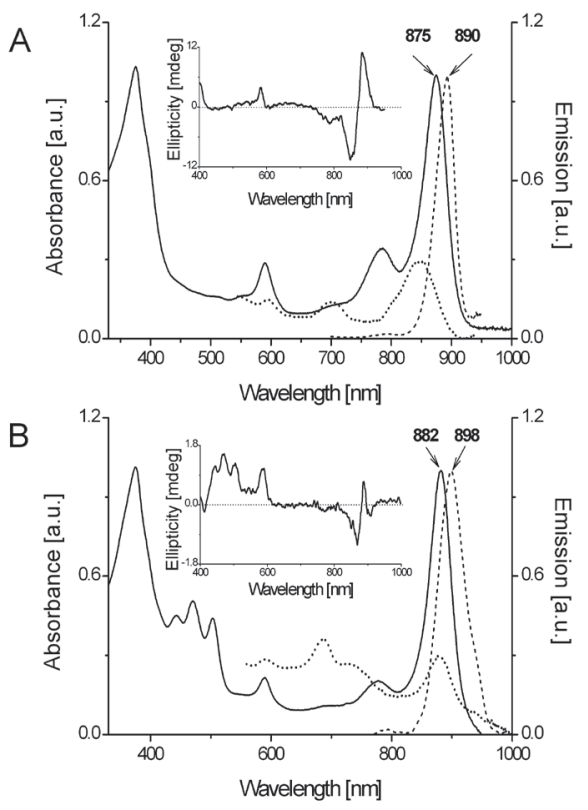

Figure 1. Normalized absorption (solid line), emission (dash line) and circular dichroism (insets) spectra of (A) the B870 complex, and (B) the Sph-binding LH1 complex.

The steady-state emission spectra were recorded upon excitation at $590 \mathrm{~nm}$ (B870) and $470 \mathrm{~nm}$ (Sph-LH1), respectively. The CD spectra were measured using a Jasco J-815 spectropolarimeter. Additionally, normalized (to 0.3 ) absorption spectra of the complexes treated with $25 \mathrm{mM} \mathrm{K}_{3} \mathrm{Fe}(\mathrm{CN})_{6}$ for $90 \mathrm{~min}$ are shown (dotted line).

nals appear in the regions of the $\mathrm{BChl} \mathrm{Q}_{\mathrm{x}}$ and $\mathrm{Sph}$ absorption bands. The CD spectrum provides a further evidence that the environment of BChl is affected by the presence of Sph.

In order to determine the effect of Crt on the stability of LH1 against chemical oxidants a series of experiments with hydrogen peroxide and potassium ferricyanide was performed. In all cases, a gradual decrease of the LH1 $\mathrm{Q}_{\mathrm{Y}}$ band was observed, accompanied by an increase of absorption at $\sim 690 \mathrm{~nm}$ (Fig. 1). The control experiments performed at room temperature in darkness showed that B870 and Sph-LH1 are stable. The decrease of the respective $\mathrm{Q}_{\mathrm{Y}}$ bands did not exceed 7\%.

B870 and Sph-LH1 were exposed to $70 \mathrm{mM}, 150 \mathrm{mM}$ or $290 \mathrm{mM} \mathrm{H}_{2} \mathrm{O}_{2}$. For example, after $5 \mathrm{~min}$ treatment of $\mathrm{B} 870$ with $70 \mathrm{mM} \mathrm{H} \mathrm{O}_{2}$ the intensity of the $\mathrm{BChl}$ $\mathrm{Q}_{\mathrm{Y}}$ band decreased by $10 \%$ (Fig. 2A). A prolonged incubation resulted in a further decrease of the absorption band by about $20 \%, 35 \%$ and $63 \%$ after 15,30 and 90 min, respectively. A decrease of the $\mathrm{Q}_{\mathrm{Y}}$ intensity was accompanied by a shift of about 1-2 nm toward longer wavelength in the $\mathrm{B} 870$. An increase in $\mathrm{H}_{2} \mathrm{O}_{2}$ concentration to $290 \mathrm{mM}$ caused a larger drop of the $\mathrm{Q}_{\mathrm{y}}$ band, by about $50 \%$ and $90 \%$ after 15 and $90 \mathrm{~min}$, respectively. A very similar B880 degradation kinetics was observed during the initial $15 \mathrm{~min}$ of the treatment of Sph-LH1 with $70 \mathrm{mM} \mathrm{H} \mathrm{O}_{2}$. At longer times, a very clear protective effect of Crt on LH1 is seen, as after 90 min the concentration of Sph-LH1 is twice as high as that of B870 (Fig. 2B). At higher concentrations of $\mathrm{H}_{2} \mathrm{O}_{2}$ only a weak effect of Sph was observed (Fig. 2B). The kinetics of emission decrease (not shown) was much faster than the one seen in the absorption but after 90 min a similar $60-70 \%$ drop occurred.

The stability of B870 and Sph-LH1 was also monitored in the presence of $\mathrm{K}_{3} \mathrm{Fe}(\mathrm{CN})_{6}$. The samples were 
B870
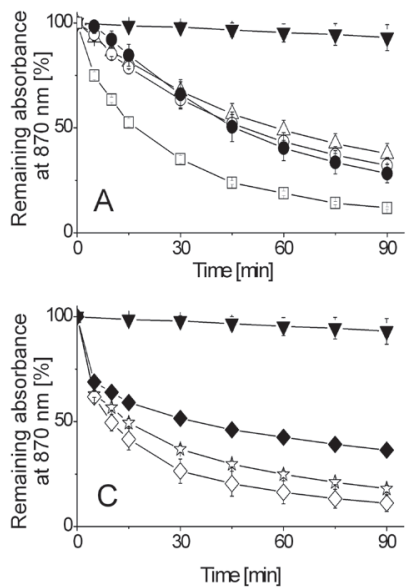

Figure 2. The stability of B870 (A, C) and Sph-LH1 (B, D) exposed to oxidants: $\mathrm{H}_{2} \mathrm{O}_{2}(A, B)$ or $\mathrm{K}_{3} \mathrm{Fe}(C N)_{6}(C, D)$, respectively, as judged from decrease of the absorbance at the $\mathrm{BChl} \mathrm{Q}_{\mathrm{Y}}$ band.

Labels: dark control $(\boldsymbol{\nabla}), 70 \mathrm{mM} \mathrm{H}_{2} \mathrm{O}_{2}(\triangle), 150 \mathrm{mM} \mathrm{H}_{2} \mathrm{O}_{2}(\mathrm{O}) ; 290 \mathrm{mM} \mathrm{H}_{2} \mathrm{O}_{2}$

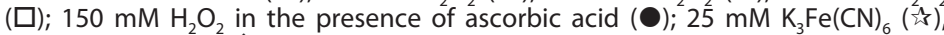
$50 \mathrm{mM} \mathrm{K} \mathrm{Ke}_{3}(\mathrm{CN})_{6}(\diamond), 50 \mathrm{mM} \mathrm{K} \mathrm{Fe}(\mathrm{CN})_{6}$ in the presence of ascorbic acid $(\diamond)$

The data represent a mean value of three independent experiments.

exposed to the following concentrations of $\mathrm{K}_{3} \mathrm{Fe}(\mathrm{CN})_{6}$ : $25 \mathrm{mM}, 50 \mathrm{mM}$ and $100 \mathrm{mM}$. For example, after 5, 30 and 90 min treatment of $\mathrm{B} 870$ with $25 \mathrm{mM} \mathrm{K} \mathrm{K}_{3} \mathrm{Fe}(\mathrm{CN})_{6}$ the intensity of the $\mathrm{BChl} \mathrm{Q}_{\mathrm{Y}}$ band decreased by about $40 \%, 65 \%$, and 82\%, respectively (Fig. 1A, 2C). At the higher concentrations of $\mathrm{K}_{3} \mathrm{Fe}(\mathrm{CN})_{6}$ the effect was stronger. The decrease of the absorption intensity was accompanied by a shift of the $B 870 \mathrm{Q}_{\mathrm{Y}}$ band toward shorter wavelengths (by about $25 \mathrm{~nm}$ ). No such a shift was observed for Sph-LH1 but the kinetics of the $Q_{Y}$ band quenching slowed down by a factor of about 2 (Fig. 2D). Again, the effect of $\mathrm{K}_{3} \mathrm{Fe}(\mathrm{CN})_{6}$ was much more pronounced in the emission from B870, causing a $90 \%$ drop after a 5 min treatment, while in Sph-LH1, the quenching reached $65 \%$ of the initial value (not shown).

Additionally, the effect of ascorbate, a well-known scavenger of ROS (Bodannes et al., 1979), on the kinetics of oxidant-induced degradation of B870 and SphLH1 was tested. In the reactions with $\mathrm{K}_{3} \mathrm{Fe}(\mathrm{CN})$, the addition of ascorbate enhanced the stability of all LH1 complexes while in the case of $\mathrm{H}_{2} \mathrm{O}_{2}$ it seemed to be effective only at the early stages of the reaction (Fig. 2A, B). As was already demonstrated by Picorel et al. (1984) in various LH1 systems, the effect of chemical oxidation with $\mathrm{K}_{3} \mathrm{Fe}(\mathrm{CN})_{6}$ can be substantially reversed $(\sim 85 \%)$ upon immediate addition of an excess of ascorbate. Since under our experimental condition the excess of ascorbate was present from the beginning we may expect that a direct reduction of ferricyanide takes place as the main antioxidant reaction.

Ascorbic acid readily undergoes a one- or two-electron reduction, yielding ascorbyl radical and dehydroascorbic acid, respectively. Ascorbate and ascorbyl radical have low reduction potentials and therefore can effectively interact with other radicals and oxidants. Moreover, ascorbate can be regenerated from both ascorbyl radical and dehydroascorbic acid (Buettner et al., 1996).

On the other hand, the antioxidant effect of ascorbate in the $\mathrm{H}_{2} \mathrm{O}_{2}$ treated complexes in not unequivocal. One possible explanation of this effect might be the formation of some reactive intermediates, which could fur- ther act as prooxidants, promoting pigment degradation. The formation of unstable and highly reactive hydroperoxide derivatives of dehydroascorbic acid has indeed been reported (Kwon et al., 1988).

In conclusion, potassium ferricyanide turned out to be a stronger oxidant than hydrogen peroxide. Both oxidants cause similar changes in the absorption spectra of the complexes, pointing out to the formation of analogous degradation products such as e.g. 2-desvinyl-2-acetylchlorophyll a, as judged from the appearance of a band at $\sim 690 \mathrm{~nm}$ in the absorption spectra (Smith et al., 1966). Picorel et al. (1984) or Law \& Cogdell (1998) have already demonstrated that oxidation of native $\mathrm{LH} 1$ complexes with $\mathrm{K}_{3} \mathrm{Fe}(\mathrm{CN})_{6}$ leads to the changes in their spectral properties. Similar changes in the absorption and emission spectra of the reconstituted Sph-LH1 complexes were seen in the present work. The comparison of the degradation kinetics clearly indicates that Crt significantly influences the stability of the complexes, however it does not prevent them from a gradual irreversible decomposition. The changes in the absorption spectra of LH1 caused by oxidants are slower than the ones in the emission signals. A more rapid drop in the emission intensity can be explained by the fact that the presence of even a small number of excitation traps (oxidized $\mathrm{BChl}$ ) may completely inhibit the intracomplex energy transfer (Law et al., 1998; Fiedor et al., 2000; Fiedor et al., 2001b).

\section{Acknowledgments}

The project was partially supported by the grant N302 195035 from Polish Ministry of Science and Higher Education and its grant for Scientific Research (AGH), and by a grant from the Foundation for Polish Science (TEAM/2010-5/3 to L.F.). The groups cooperate within the BIONAN project.

\section{REFERENCES}

Akahane J, Rondonuwu FS, Fiedor L, Watanabe Y, Koyama Y (2004) Dependence of singlet-energy transfer on the conjugation length of carotenoids reconstituted into the LH1 complex from Rhodospirillum rubrum G9. Chem Phys Lett 393: 184-191.

Bodannes RS, Chan PC (1979) Ascorbic acid as a scavenger of singlet oxygen. FEBS Lett 105: 195-196.

Britton G (1995) Structure and properties of carotenoids in relation to function. FASEB J 9: 1551-1558.

Buettner GR, Jurkiewicz BA (1996) Catalytic metals, ascorbate and free radicals: combination to avoid. Radiat Res 145: 532-541.

Chang MC, Callahan PM, Parkes-Loach PS, Cotton TM, Loach PA (1990) Spectroscopic characterization of the light-harvesting complex of Rhodospirillum rubrum and its structural subunit. Biochemistry 29: 421-429.

Cogdell RJ, Fyfe PK, Barrett SJ, Prince SM, Freer AA, Isaacs NW, McGlynn P, Hunter CN (1996) The purple bacterial photosynthetic unit. Photosynth Res 48: 55-63.

Davidson E, Cogdell RJ (1981) Reconstitution of carotenoids into the light-harvesting pigment-protein complex from the carotenoidless mutant of Rhodopseudomonas sphaeroides R26. Biochim Biophys Acta 635: 295-303.

Davis CM, Bustamante PL, Loach PA (1995) Reconstitution of the bacterial core light-harvesting complexes of Rhodobacter sphaeroides and Rhodospirillum rubrum with isolated $\alpha$ - and $\beta$-polypeptides, bacteriochlorophyll a, and carotenoid. J Biol Chem 270: 5793-5804.

Fiedor J (2007) Photoprotective and structural functions of carotenoids in model photosynthetic complexes. Ph.D. Thesis, Jagiellonian University, Cracow.

Fiedor J, Fiedor L, Haessner R, Scheer H (2005) Cyclic endoperoxides of $\beta$-carotene, potential pro-oxidants, as products of chemical quenching of singlet oxygen. Biochim Biophys Acta 1709: 1-4. 
Fiedor J, Fiedor L, Kammhuber N, Scherz A, Scheer H (2002) Photodynamics of the bacteriochlorophyll-carotenoid system. 2. Influence of central metal, solvent and $\beta$-carotene on photobleaching of bacteriochlorophyll derivatives. Photochem Photobiol 76: 145-152.

Fiedor J, Fiedor L, Winkler J, Scherz A, Scheer H (2001a) Photodynamics of the bacteriochlorophyll-carotenoid system. 1. Bacteriochlorophyll-photosensitized oxygenation of $\beta$-carotene in acetone. Photochem Photobiol 74: 64-71.

Fiedor J, Pilch M, Fiedor L (2009) Tuning the thermodynamics of association of transmembrane helices. J Phys Chem B 113: 1283112838.

Fiedor L (2006) Hexacoordination of bacteriochlorophyll in photosynthetic antenna LH1. Biochemistry 45: 1910-1918.

Fiedor L, Akahane J, Koyama Y (2004) Carotenoid-induced cooperative formation of bacterial photosynthetic LH1 complex. Biochemistry 43: 16487-16496.

Fiedor L, Leupold D, Teuchner K, Voigt B, Hunter CN, Scherz A, Scheer H (2001b) Excitation trap approach to analyze size and pigment-pigment coupling: Reconstitution of LH1 antenna of Rhodobacter sphaeroides with Ni-substituted bacteriochlorophyll. Biochemistry 40: 3737-3747.

Fiedor L, Scheer H, Hunter CN, Tschirschwitz F, Voigt B, Ehlert J, Nibbering E, Leupold D, Elsaesser T (2000) Introduction of a 60 fs deactivation channel in the photosynthetic antenna LH1 by NiBacteriopheophytin a. Chem Phys Lett 319: 145-152.

Frank HA (1999) Incorporation of carotenoids into reaction center and light-harvesting pigment-protein complexes. In The photochemistry of carotenoids. Frank HA, Young AJ, Britton G, Cogdell RJ eds, pP 235-244. Kluwer Academic Publishers, Dordrecht.

Fujii R, Onaka K, Kuki M, Koyama Y, Watanabe Y (1998) The 2Agenergies of all-trans-neurosporene and spheroidene as determined by fluorescence spectroscopy. Chem Phys Lett 288: 847-853.

Ghosh R, Hauser H, Bachorn R (1988) Reversible dissociation of the B873 light harvesting complex from Rs. rubrum G-9+. Biochemistry 27: 1004-1014.

Gomez I, Sieiro C, Ramirez JM, Gomez-Amores S, del Campo FF (1982) The antenna system of Rhodospirillum rubrum: radical formation upon dark oxidation of bulk bacteriochlorophyll. FEBS Lett 144: $117-120$.

Koepke J, Hu X, Muenke C, Schulten K, Michel H (1996) The crystal structure of the light-harvesting complex II (B800-850) from Rhodospirillum molischianum. Structure 4: 581-597.
Kwon B-M, Foote CS (1988) Chemistry of singlet oxygen. 50. Hydroperoxide intermediates in the photooxygenation of ascorbic acid. $J$ Am Chem Soc 110: 6582-6583.

Law CJ, Cogdell RJ (1998) The effect of chemical oxidation on the fluorescence of the LH1 (B880) complex from the purple bacterium Rhodobium marinum. FEBS Lett 432: 27-30.

Loach PA, Parkes-Loach PS (1995) Structure-function relationships in core light-harvesting complexes (LHI) as determined by characterization of the structural subunit and by reconstitution experiments. In Anoxygenic Photosynthetic Bacteria. Blankenship RE, Madigan MT, Bauer CE eds, pp 437-471. Kluwer Academic Publishers, Dordrecht.

McDermott G, Prince SM, Freer AA, Hawthornthwaite-Lawless AM, Papiz MZ, Cogdell RJ, Isaacs NW (1995) Crystal structure of an integral membrane light-harvesting complex from photosynthetic bacteria. Nature 374: 517-521.

Miller JF, Hinchigeri SB, Parkes-Loach PS, Callahan PM, Sprinkle JR, Riccobono JR, Loach PA (1987) Isolation and characterization of a subunit form of the light-harvesting complex of Rhodospirillum rubrum. Biochemistry 26: 5055-5062.

Noguchi T, Hayashi H, Tasumi M (1990) Factors controlling the efficiency of energy transfer from carotenoids to bacteriochlorophyll in purple photosynthetic bacteria. Biochim Biophys Acta 1017: 280-290.

Pandit A, Visschers RW, Stokkum van IHM, Kraayenhof R, Grondelle van R (2001) Oligomerization of light-harvesting I antenna peptides of Rhodospirillum rubrum. Biochemistry 40: 12913-12924.

Picorel R, Belanger G, Gingras G (1983) Antenna holochrome B880 of Rhodospirillum rubrum S1. Pigment, phospholipid, and polypeptide composition. Biochemistry 22: 2491-2497.

Picorel R, Lefebvre S, Gingras G (1984) Oxido-reduction of B800-850 and $\mathrm{B} 880$ holochromes isolated from three species of photosynthetic bacteria as studied by electron-paramagnetic resonance and optical spectroscopy. Eur J Biochem 142: 305-311.

Smith JR, Calvin M (1966) Studies on the chemical and photochemical oxidation of bacteriochlorophyll. I Am Chem Soc 88: 4500-4503.

Strugis JN, Robert B (1994) Thermodynamics of membrane polypeptide oligomerization in light-harvesting complexes and associated structural changes. J Mol Biol 238: 445-454. 